ABDI: Jurnal Pengabdian dan Pemberdayaan Masyarakat ISSN: 2656-369X (Print), 2684-8570 (Online)

Volume 2 No. 1, Juni 2020

http://abdi.ppj.unp.ac.id/index.php/abdi

Email: abdi@ppi.unp.ac.id

DOI: https://doi.org/10.24036/abdi.v2il.39

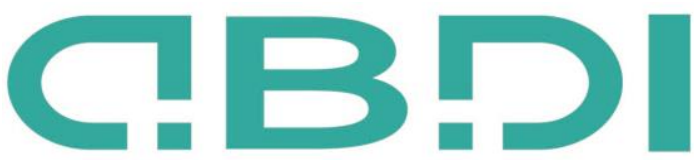

ABDI: JURNAL PENGABDIAN DAN PEMBERDAYAAN MASYARAKAT

\title{
Pemberdayaan Keluarga Muallaf Pra-Sejahtera di Kelurahan Sumarambu Kecamatan Telluwanua Kota Palopo Provinsi Sulawesi Selatan
}

\author{
Nur Saqinah Galugu ${ }^{1}$, Sumarlin Sumarlin ${ }^{2}$ \\ Jurusan Bimbingan Konseling, Universitas Muhammadiyah Palopo \\ 2 Jurusan Pendidikan Guru Anak Usia Dini (PGPAUD), Universitas Muhammadiyah Palopo \\ E-mail: saqina.galugu@gmail.com, sumarlin01@umpalopo.ac.id
}

\begin{abstract}
Abstrak
Dari hasil pengamatan pada keluarga Muallaf ditemukan beberapa masalah yakni; (1) Lemahnya kemampuan masyarakat dalam literasi Baca Tulis Al-Qur'an (2) Lemahnya kapasitas keagamaan pada keluarga muallaf khususnya dasar-dasar agama yang meliputi aqidah, ibadah, dan dasar muamalah; (3) Lemahnya kesejahteraan ekonomi mayarakat. Adapun solusi yang ditawarkan yakni (1) Pendampingan Baca Tulis Al-Qur'an secara rutin pada sore hari baik bagi ibu rumatangga maupun pada anaak-anak(2) Pengajian Rutin yang difokuskan pada dasar-dasar agama Islam seperti tauhid dan ibadah higga ibadah praktis dan (3) Workshop Kewirausahaan yang berfokus pada motivasi untuk berwirausaha dan praktek pengolahan pangan lokal yakni sagu.
\end{abstract}

Kata Kunci: Baca Tulis Al-Qur'an, Muallaf, Sagu

\section{Abstract}

From the observation results on the Muallaf Family, There were several problems found, which are: (1) Lack of ability for the community in reading and writing literacy of the Qur'an. (2) Lack of religious capacity for Muallaf family, especially the basic of religious matter, including aqidah, ibadah, and basic muamalah; (3). The weak of the economic welfare for the society. The solutions offered are (1)Assistance in Recitation of reading and writing Qur'an regularly on the evening both for the house wives and the children.(2) Regular study which focuses on the basic of Islam such as Tauhid and Ibadah as well as practical ibadah, and (3) entrepreneurship workshop which focuses on motivating the society to be an entrepreneur and local food processing practices which is Sagu.

Keywords: Muallaf, Reading and writing of the Qur'an, Sagu

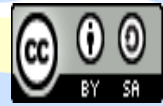





\section{Pendahuluan}

Program Kuliah Kerja Nyata-Pembelajaran Pemberdayaan Masyarakat (KKN-PPM) saat ini diarahkan pada perubahan konsep "working with community" menjadi "working for the community". Selain itu, untuk menjaga kontekstualisasinya, KKN-PPM dilakukan dengan mengubah paradigm pembangunan (development) menjadi paradigma pemberdayaan (empowerment). Atas dasar hal tersebut di atas, revitalisasi Kuliah Kerja Nyata menjadi Kuliah Kerja Nyata- Pembelajaran Pemberdayaan Masyarakat (KKN-PPM) Perguruan Tinggi (PT) di seluruh Indonesia sangatlah penting untuk dilakukan sebagai bagian dari tugas perguruan tinggi (Kemristek Dikti, 2017).

Kota Palopo adalah daerah yang mayoritas penduduknya menganut agama Islam, sejalan dengan hal tersebut maka tempat peribadatan bagi penganut agama Islam terlihat jauh lebih banyak dari agama yang lain, sampai dengan keadaan akhir tahun 2015 jumlah Masjid sebanyak 174 unit, mushola 45 sehingga jumlah tempat ibadah untuk ummat muslim sebanyak 219. Sementara tempat ibadah umat Nasrani masing- masing tercatat hanya 68 unit gereja Protestan dan 5 unit gereja Katolik berikut untuk ummat Budha 2 unit dan Hindu 1 unit. Perjumpaan suku, etnis, dan agama dalam suasana damai, salah satu konsekwensi dari interaksi tersebut adalah konvergensi dan konversi agama, yang dalam konteks Islam disebut dengan muallaf.

Kelurahan Sumarambu terletak di kecamatan Telluwanua, dengan jarak 17 kilometer ke arah barat, kawasan perbukitan dan pegunungan. Jumlah Penduduk kelurahan Sumarambu sebanyak 1.371 jiwa. Pemeluk agama Islam sebanyak 1.264 jiwa, Protestan sebanyak 87 jiwa, Katolik sebanyak 20 jiwa. Sedangkan tempat ibadah terdiri dari masjid sebanyak 5 buah, dan gereja sebanyak 1 buah. Islam menjadi agama mayoritas karena banyak penganut agama lain yang melakukan konversi agama menjadi muslim. Umumnya, para muallaf berprofesi sebagai buruh kasar, kerja serabutan, dan petani, dengan tingkat pendidikan mayoritas adalah sekolah dasar.

Muallaf dalam Kamus Besar Bahasa Indonesia didefinisikan sebagai orang yang baru masuk Islam. Dalam konteks kehidupan sehari-hari di masyarakat, kata muallaf menunjuk pada orang yang ke-Islamannya tidak sejak lahir. Muallaf berasal dari bahasa Arab yang berarti tunduk, menyerah, dan pasrah. Sedangkan, dalam pengertian Islam, muallaf digunakan untuk menunjuk seseorang yang baru masuk agama Islam (Wulandari, 2012).

Jika diidentifikasi, maka secara garis besar konversi agama terjadi karena dorongan dari dalam diri (endogenous origin), yaitu proses perubahan yang terjadi dalam diri seseorang atau kelompok (Hamali, 2012). Konversi yang terjadi dalam batin ini membentuk suatu kesadaran untuk mengadakan suatu transformasi disebabkan oleh krisis yang terjadi dan keputusan yang di ambil seseorang berdasarkan pertimbangan pribadi. Sedangkan konversi agama akibat unsur dari luar (exogenous origin), yaitu proses perubahan yang berasal dari luar diri atau kelompok sehingga mampu menguasai kesadaran orang atau kelompok yang bersangkutan. Kekuatan yang berasal dari luar ini kemudian menekan pengaruhnya terhadap kesadaran mungkin berupa tekanan batin, sehingga memerlukan penyelesaian oleh yang bersangkutan (Wardefi, 2019).

Terdapat tiga persoalan mendasar yang sering dialami oleh muallaf di kelurahan Sumarambu kota Palopo. Pertama, angka melek aksara Al-Qur'an masih sangat rendah. Secara umum, data survei Institut Ilmu Al-Qur'an (IIQ) Jakarta pada tahun 2015, menyebutkan bahwa 65 persen umat Islam di Indonesia ternyata masih buta aksara Al-Qur'an. Sebanyak 35 persennya hanya bisa membaca Al-Quran saja. Sedangkan yang membaca dengan benar hanya 20 persen. Data Yayasan Muallaf Palopo menyebutkan bahwa di antara sepuluh muallaf yang ada di kelurahan Sumarambu, delapan orang muallaf tidak dapat membaca dan menulis Al- Qur'an. Ini terjadi pada anak-anak berusia 07-17 tahun. Berarti, angka melek baca tulis Al- Qur'an pada orang tua akan lebih rendah, karena keterbatasan waktu dan kurangnya akses mereka terhadap media.

Kedua, rendahnya pemahaman terhadap dasar-dasar agama, maupun pengamalan praktis ajaran Islam. Secara geografis kelurahan Sumarambu merupakan daerah yang cukup jauh untuk dijangkau oleh para Muballigh maupun aktivis Islam. Bahkan, beberapa masjid sering tidak melaksanakan salat Jumat karena tidak adanya warga sekitar yang dapat menjadi khatib. Sehingga, muallaf yang telah dengan sukarela memeluk Islam mengalami stagnasi dan kegersangan spiritualitas mereka. Pemahaman para muallaf 
terhadap dasar Islam seperti aqidah dan ibadah dan fiqh praktis seperti fiqh salat, fiqh zakat, fiqh jenazah, fiqh wanita, dan persoalan praktis lainnya, masih sangat rendah.

Ketiga, mayoritas muallaf di kelurahan Sumarambu berprofesi sebagai petani, dan secara ekonomi hidup pada zona menengah ke bawah. Data BPS Kota Palopo lewat data dasar PPLS 2014, menghasilkan sekitar 7.119 RTS. Sebagian besar dari keluarga yang ada di Kota Palopo masuk dalam kategori Keluarga Sejahtera III sebanyak 12.315 keluarga. Sedangkan untuk keluarga Pra Sejahtera hanya tercatat sebanyak 5.583. Kecamatan Teluwanua terdiri dari 2.445 kepala keluarga, dan sebanyak 1.253 (51.25 \%) sebagai Rumah Tangga Sasaran. Permasalahan yang dialami oleh muallaf di kelurahan Sumarambu tentu menjadi persoalan bersama yang kemudian harus segera ditemukan solusinya. Hal tersebut menjadi dasar pemikiran bagi kami pengabdi untuk melakukan pengabdian dan pemberdayaan masyarakat di kelurahan Sumarambu dengan mengangkat tema Pemberdayaan Muallaf.

\section{Metode Pelaksanaan}

Program KKN-PPM dilaksanakan dengan memadukan beberapa model pola pemberdayaan masyarakat yang telah populer yakni: Model eko-efesiensi (eco-development), Model Center for Environment and Society dan Model Enthrepreneurship Capasity Building (ECB). Model eko-efesiensi (eco-development). Konsep eko-efesiensi yang oleh diartikan sebagai perpaduan sinergis antara komponen ekologi dan ekonomi. Eko-efesiensi bertujuan memperoleh efesiensi dari aspek ekonomi maupun ekologi yang menyangkut keberlanjutan lingkungan hidup sebagai penopang kehidupan manusia (Soemarwoto, 2001). Program Kemitraan Masyarakat ini didesain untuk meningkatkan proses kemandirian dan pemberdayaan sasaran namun tidak meninggalkan hubungan yang simbiosis dengan lingkungan hidup serta jaminan keberlanjutan pada masa mendatang.

Model Center for Environment and Society didefinisikan sebagai suatu usaha berkelanjutan yang merupakan suatu cara memanfaatkan barang alamiah dan jasa yang tidak merusak lingkungan dan memanfaatkan pengetahuan serta keterampilan mitra yang dipilih. Model ini juga dapat diterapkan yaitu dengan memanfaatkan penggunaan secara produktif "social capital" dalam memecahkan permasalahan masyarakat yang monoton dalam mengolah Sagu menjadi olahan pangan. Unsur social capital yang dapat dijadikan faktor pendukung pelaksanaan program kegiatan ini salah diantaranya adalah konsep Tudang Sipulung (duduk bersama menyelesaikan masalah), yang berujung pada meningkatnya sikap gotong royong.

Model Enthrepreneurship Capasity Building (ECB) terkait erat dengan kemampuan berwirausaha dari masyarakat, dengan model ini diharapkan: (1) memberikan wawasan, sikap, dan keterampilan usaha, (2) memberikan peluang, (3) memfasilitasi, dan (4) memonitor dan mengevaluasi (Kurana, 2008). Selain memadukan tiga model pemberdayaan masyarakat di atas, pengabdi juga memanfaatkan teknologi tepat guna untuk melakukan pengolaan sagu menjadi berbagai hasil olahan yang akan membantu muallaf dalam meningkatkan taraf kesejahteraan ekonomi mereka.

\section{Hasil dan Pembahasan}

Salah satu tahapan penting dalam kegiatan Program KKN-PPM "Pemberdayaan Keluarga Muallaf di kelurahan Sumarambu Kecamatan Telluwanua Kota Palopo Provinsi Sulawesi Selatan", adalah melakukan kordinasi dengan warga khususnya ibu-ibu dan kaum perempuan yang memiliki potensi ekonomi melalui usaha rumahan. Selain itu, para muallaf juga didata dan diorganisir agar diperoleh jumlah yang pasti serta memudahkan dalam proses pemberdayaan. Komponen yang dilibatkan dalam proses ini adalah pemerintah, tokoh agama, tokoh masyarakat, tokoh pemuda, dan tokoh perempuan yang dipandang memiliki akses terhadap warga yang akan diberdayakan. Pendekatan yang digunakan diantaranya adalah Enthrepreneurship Capasity Building (ECB) yang terkait erat dengan kemampuan berwirausaha dari masyarakat, dengan model ini diharapkan: (1) memberikan wawasan, sikap, dan keterampilan usaha, (2) memberikan peluang, (3) memfasilitasi, dan (4) memonitor dan mengevaluasi, dipadukan dengan Religiousity Capasity Building ( $R C B$ yang diarahkan pada peningkatan kemampuan religiusitas keluarga muallaf.

Selanjutnya bimbingan Baca Tulis Al-Qur'an dan peningkatan kapasitas keagamaan. Sasaran utamanya adalah keluarga muallaf yang mayoritas adalah kaum perempuan dan anak-anak. Kegiatan KKN-PPM telah berhasil meningkatkan kemampuan Baca Tulis Al-Qur'an dan kapasitas keagamaan

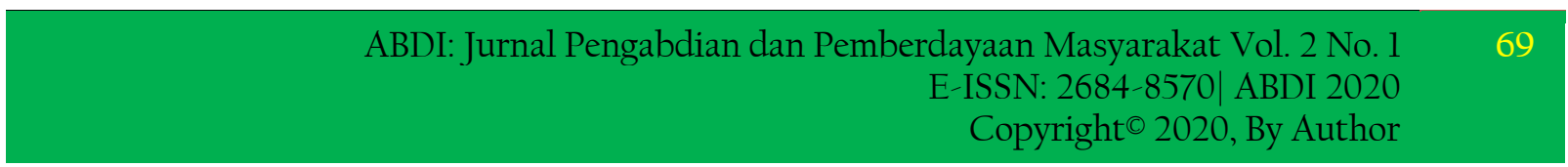


keluarga muallaf. Beberapa orang telah mampu membaca al-Qur'an dengan baik dan praktik ibadah praktis seperti wudhu, tayammum, mandi wajib, salat, dan penyelenggaraan jenazah dengan benar.

Bimbingan baca tulis al-Qur'an menggunakan metode al-barqy dinilai efektif untuk meningkatkan kemampuan baca tulis al-qur'an mualllaf. Metode al-barqy merupakan metode pembelajaran al-Qur'an yang memiliki ciri khas mudah, menggembirakan, anti lupa dan cepat. Metode ini sangat cocok digunakan bagi usia anak-anak dan juga orangtua karena metode ini sangat menarik dengan menggunakan kata-kata atau kalimat sehari-hari yang mudah diingat ( Sari, 2017). Metode ini menggunakan metode semi SAS sistematikanya pengamatan global, memisah, memilih, dan memadu artinya metode al-Barqy memiliki kemampuan dalam memisah huruf, memadu bunyi satu huruf dan perkataan serta diusahakan setiap struktur mempunyai arti dan mudah diingat.

Kegiatan keagamaan merupakan sarana untuk syiar agama, dengan harapan masyarakat semakin mengerti dan memahami hal-hal yang dianjurkan dan yang dilarang dalam agama (Nuh, 2010). Peningkatan pemahaman dasar-dasar agama dilakukan degan metode ceramah, diskusi dan memanfaatkan media audiovisual sehingga memudahkan bagi para muallaf untuk memahami dan mempraktekkan ibadah praktis seperti wudhu, sholat, tayammum dan mandi wajib.

Selain pembinaan keagamaan, pemberdayaan muallaf juga berfokus pada peningkatan kesejahteraan ekonomi melalui pengolahan potensi alam yang ada di daerah tersebut. Sumarambu merupakan salah satu daerah dengan potensi alamnya yakni sagu yang memiliki potensi untuk dapat diolah sehingga dapat meningkatkan kesejahteraan ekonomi muallaf. Sagu merupakan sumber pangan potensial dan juga fungsional yang dapat dikembangkan dan diolah dengan berbagai macam olahan dikarenakan kandungan karbohidrat yang tidak jauh berbeda dari beras dan jagung (Alfons \& Rivaie, 2011).

Muallaf di kelurahan Sumarambu telah berhasil melakukan penganekaragaman pengelolaan sagu menjadi tepung, bagea, kerupuk sagu dan juga brownis sagu yang tentunya mampu meningkatkan daya tarik masyarakat terhadap sagu dan dapat dijadikan sebagai nilai tambah bagi kesejahteraan ekonomi muallaf dan warga Sumarambu secara umum. Sagu yang mulanya hanya dijadikan makanan khas seperti kapurung, lanya' dan beberapa jenus makanan tradisional lainnya kini dapat diolah menjadi kue yang sangat kekinian dan digemari masyarakat luas.

Dari hasil kajian dikemukakan bahwa dari indikator variable product yang terdiri dari: 1.) Kualitas; 2.) Fitur Produk; 3.) Bahan Baku; 4.) Kemasan; dan 5.) Merek UKM Multi Kue berada pada kuadran I yang berarti strategi yang dianjurkan adalah strategi Strengths Opportunities (SO) atau disebut sebagai strategi Growth. Kuadran I menunjukkan bahwa UKM Multi Kue tergolong dalam usaha yang berkembang dan memiliki posisi yang kuat dan berpeluang. Strategi-strategi yang didapatkan yaitu menjamin kualitas produk yang ditawarkan demi membangun citra yang baik di mata konsumen dengan mempertahankan dan memperhatikan kekonsistensian kualitas produk serta selalu berinovasi pada produk agar dapat bersaing (Padhil dkk, 2018).

\section{Kesimpulan}

Muallaf merupakan tugas dan tanggungjawab kita sebagai muslim dan juga sebagai akademisi untuk memfasilitasi peningkatan kualitas diri dan juga kesejahteraan ekonomi mereka. Pendampingan baca-tulis al-Qur'an dengan metode al-Barqy sangat bermanfaat bagi muallaf, demikian juga dengan penanaman pengetahuan dasar Islam melalui metode ceramah, diskusi dan pemanfaatan media audiovisual. Peningkatan kesejahteraan ekonomi dan kemauan berwirausaha juga merupakan hal penting bagi muallaf. Oleh karena itu muallaf perlu untuk diberikan bimbingan pengolahan potensi alam yang ada di daerah tersebut, misalnya sagu diolah menjadi kue atau makanan modern yang digemari oleh masyarakt umum. 


\section{Daftar Pustaka}

Alfonfs, J. B \& Rivaie, A. (2011). Sagu Mendukung Ketahanan Pangan Dalam Menghadapi Dampak Perubahan Iklim, Perspektif, 10(2), 81 -91.

Hamali, S. (2012). Dampak Konversi Agama Terhadap Sikap dan Tingkah Laku Keagamaan Individu. Al-Adyan, 7(12), 21-40

Nuh, N M. (2010). Aliran-Aliran Keagmaan Aktual di Indonesia. Jakarta: Moloho Jaya Abadi Press.

Kementrian Riset, Teknologi dan Pendidikan Tinggi Republik Indonesia. (2017). Panduan Penelitian dan Pengabdian Kepada Masyarakat di Perguruan Tinggi. Jakarta: Direktorat Riset dan Pengabdian Kepada Masyarakat.

Wulandari, V. (2012). Perbandingan Religiusitas Tokoh Muallaf Dalam Novel Ayat-Ayat Cinta. Jurnal pendidikan dan sastra indonesia, 1(1), 247-249.

Padhil, A., Saleh, A., Nusran, M., Ismail, H., \& Aidel, A. (2018). Strategi Pemasaran Kue bagea sebagai Kue Khas Kota palopo dengan Menggunakan Analisis SWOT pada UKM Multi Kue Kota Palopo. Journal of Industrial Engineering Management, 3(2), 15-23.

Soemarwoto, O. (2001). Ekologi, Lingkungan dan Pembangunan. Jakarta: Djambatan.

Wardefi, R. (2019). Bimbingan Pra Nikah Bagi Calon Pengantin dalam Membentuk Keluarga Sakinah di Kanagarian Kambang Kecamatan Lengayang Kabupaten Pesisir Selatan. ABDI: Jurnal Pengabdian dan Pemberdayaan Masyarakat, 1(2), 50-57. https://doi.org/10.24036/abdi.v1i2.10

Widjono, A., R. Aser, dan Amisnaipa. (2000). Identifikasi, Karakterisasi, dan Koleksi Jenis Jenis Sagu. Prosiding Seminar Hasil-Hasil Sistem Usaha Tani Papua. Pusat Penelitian Sosial Ekonomi Pertanian: Bogor.

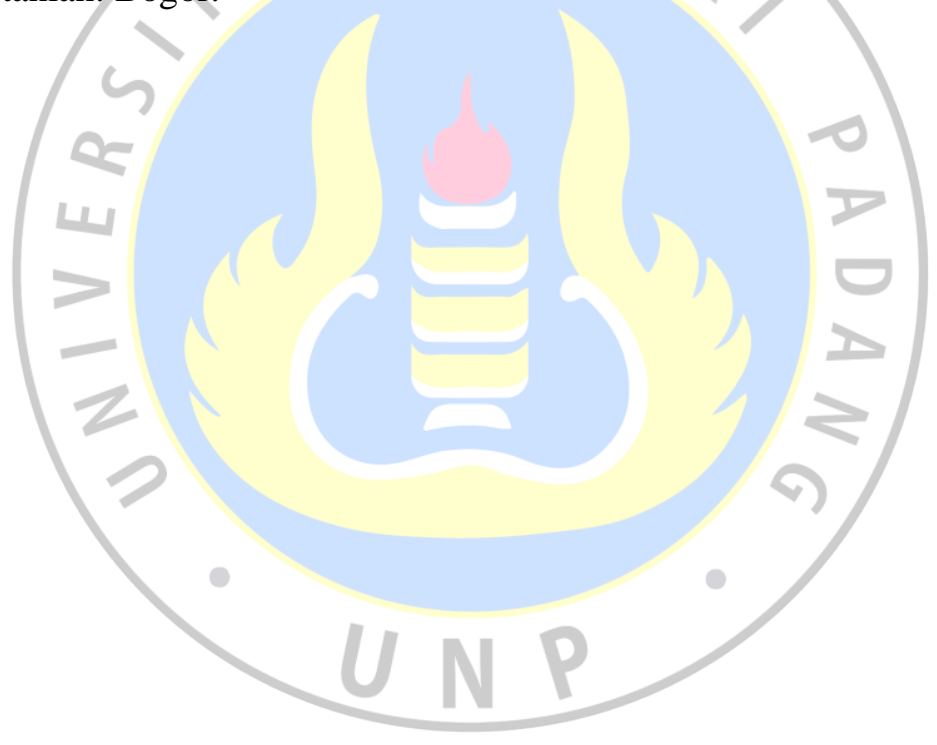

